\title{
PREVALENCE OF OVERWEIGHT AND OBESITY IN 8 TO 15 YEAR-OLD CHILDREN IN SIDI- BEL-ABBES, ALGERIA
}

M.B. Khaled, M. Diaf

Djillali Liabes University of Sidi Bel Abbes Faculty of Sciences, Sidi Bel Abbes, Algeria

Introduction: The prevalence of childhood obesity has been dramatically increasing worldwide. This study was performed to estimate the prevalence of overweight and obesity in school children age 8 to 15 years in Sidi-Bel-Abbes (north-western region of Algeria).

Methods: A cross-sectional study was performed from February through May 2008 on 428 school children ( 218 boys and 210 girls) aged 8-15 years in the urban area of Sidi-Bel-Abbes. Their height and weight were measured and body mass index (BMI) was calculated. Overweight, obese and underweight were defined using three different international reference values for BMI: the International Obesity Task Force cut-offs to define overweight and obesity, the French references to define thinness and overweight $\left(3^{\text {rd }}\right.$ and $97^{\text {th }}$ percentiles, respectively) and the Centre for Disease Control 2000 references to define thinness, overweight and obesity $\left(5^{\text {th, }} 85^{\text {th }}\right.$ and $95^{\text {th }}$ percentiles respectively).

Results: According to the IOTF, French and CDC references, the overall prevalence rates of overweight was $7.94,7.71$ and $7.23 \%$, respectively. Obesity affected $3.73,3.73$ and $4.43 \%$, respectively. Underweight was found in 3.96 and $8.17 \%$ of children according to the French and CDC references. Girls had a higher prevalence of overweight than boys did at all ages, while boys had a higher prevalence of obesity.

Conclusion: The prevalence rate of overweight and obesity in Algerian children is considered to be high. This is a major public health problem requiring preventive intervention to avoid future health consequences in adulthood. 